\title{
Originals
}

\section{Implanted Constant Basal Rate Insulin Infusion Devices for Type 1 (Insulin-Dependent) Diabetic Patients}

\author{
H. Kritz ${ }^{1,3}$, G. Hagmüller ${ }^{2}$, R. Lovett ${ }^{3}$ and K. Irsigler ${ }^{1,3}$ \\ ${ }^{1}$ Metabolic and ${ }^{2}$ Surgical Departments, City Hospital Vienna-Lainz, and the ${ }^{3}$ Ludwig Boltzmann Institute for Metabolic Diseases and Nutrition, \\ Vienna, Austria
}

\begin{abstract}
Summary. A multi-phase study was undertaken to compare the metabolic effect on unstable Type 1 diabetic patients of optimized conventional treatment with that of external or implantable insulin delivery devices. External units were programmed to simulate implantable constant basal rate insulin infusion pumps with additional insulin doses given by subcutaneous injection or delivered by the pump. The study was continued using external devices with an optimal, meal-adjusted insulin profile simulating programmable, remote-controlled, implantable devices. Such good metabolic control was
\end{abstract}

achieved using the constant insulin infusion, supplemented by two subcutaneous injections of insulin daily, that it justified the implantation of constant rate pumps in five Type 1 patients. Patients with the implanted devices achieved a nearnormal life style, experienced significantly fewer hypoglycaemic reactions and had significantly improved glycosylated haemoglobin $\mathrm{A}_{1}$ and mean blood glucose values.

Key words: Type 1 diabetes, implantation, insulin pump, basal rate infusion.
In our experience [1-6], external pumps can be useful for short-term metabolic control, such as during pregnancy, but they are impractical for long-term use. When the subcutaneous route is chosen, they may not provide adequate metabolic control [6-8]. When the intravenous or intraperitoneal routes are used [5-7], the patient cannot remove the pump for sport, to bathe, or for sexual intercourse. Therefore, we feel that for long-term use, insulin delivery devices should be implanted completely.

The development of implantable devices has taken two directions. One very sophisticated type of machine is remote-controlled, programmable and can adapt to many possible variables [9]. A second type of pump, originally designed to deliver heparin and chemotherapeutic drugs, has been adapted for the delivery of insulin [10]. This rather simple machine, with no rotating parts, is sturdy and reliable [11]. Drugs mixed with a viscous liquid (which acts as the carrier) are forced through a capillary tube under gas pressure at a fixed rate. A pump of this type (Infusaid, Norwood, Massachusetts, USA) was first implanted by Buchwald, et al., in a Type 2 (non-insulin-dependent) diabetic patient [12].

In April 1981, before the present study, we performed three implantations: a programmable, remotecontrolled, adjustable insulin pump (Siemens, Erlangen, FRG) into a Type 1 diabetic patient [13] and two Infusaid pumps into two Type 2 diabetic patients [14]. Although the prototype of the Siemens pump had to be removed because of technical breakdown, and a newly implanted pump also failed, both of the originally implanted Infusaid machines are still in continuous use.

It was felt that the results of this early work, and those of the pilot study, justified the implantation of constant basal rate pumps (Infusaid) into four Type 1 diabetic patients and into one pancreatectomized patient. We report the results of more than 530 patient days with this method of treatment.

\section{Subjects and Methods}

\section{Patients}

Characteristics of the patients are shown in Table 1 . All were within $10 \%$ of their ideal body weight. C-peptide levels were measured before and $6 \mathrm{~min}$ after glucagon stimulation (1 $\mathrm{mg}$, IV) and the mean $( \pm S D$ ) peak value was $0.08 \pm 0.04 \mathrm{pmol} / \mathrm{ml}$.

\section{Diabetic Instability}

Criteria for quantifying instability included frequency of ketoacidosis, incidence of hypoglycaemic episodes (where the patient was able to recognize and relieve hypoglycaemic symptoms himself by ingesting carbohydrates), incidence of hypoglycaemic attacks (where severe symptoms could not be relieved by the patient alone) and number of hospital in-patient days per year. The large number of periods in hospital arose from the degree of metabolic derangement and/or unsuccessful efforts to achieve stabilization at other treatment centres.

\section{Parameter of Metabolic Control}

The degree of metabolic control was quantified by using mean blood glucose values, determined from weekly blood glucose profiles con- 
Table 1. Patient characteristics with parameters of metabolic control and insulin usage

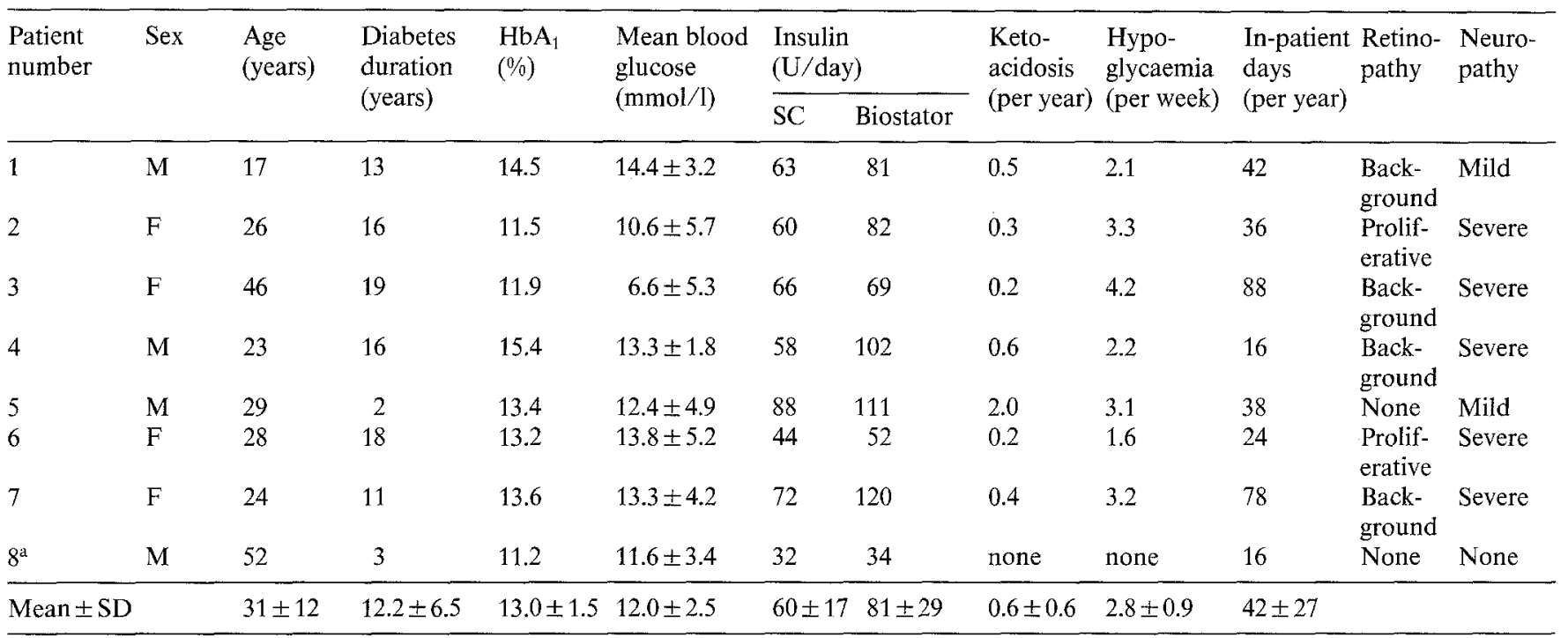

${ }^{a}$ Patient pancreatectomized. Results expressed as mean \pm SD. Patients $1-5=$ pilot study; patients 1, 2,6, 7 and $8=$ implant study. Mild neuropathy $=$ motor nerve conduction velocity $<20$ meters $/$ s; severe neuropathy $=$ motor nerve conduction velocity 2 SD lower than normal age-dependent values

Table 2. Metabolic control and insulin usage during pilot study

\begin{tabular}{|c|c|c|c|c|}
\hline & Phase 1 & Phase 2 & Phase 3 & Phase 4 \\
\hline $\begin{array}{l}\text { Mean blood } \\
\text { glucose } \\
(\mathrm{mmol} / \mathrm{l})\end{array}$ & $12.9 \pm 3.4$ & $7.7 \pm 2.2$ & $8.4 \pm 2.3$ & $7.6 \pm 2.1$ \\
\hline $\mathrm{HbA}_{1}(\%)$ & $12.8 \pm 1.5$ & $9.7 \pm 0.8$ & $10.4 \pm 1.0$ & $8.7 \pm 0.7$ \\
\hline $\begin{array}{l}\text { Hypoglycaemia/ } \\
\text { week }\end{array}$ & $1.9 \pm 0.8$ & $1.1 \pm 0.9$ & $0.9 \pm 0.6$ & $0.8 \pm 0.4$ \\
\hline $\begin{array}{l}\text { Insulin usage } \\
(U / \text { day })\end{array}$ & $65 \pm 10$ & $48 \pm 9$ & $49 \pm 7$ & $43 \pm 11$ \\
\hline
\end{tabular}

Results expressed as mean $\pm \mathrm{SD}$. Phase $1=$ intensified conventional treatment; phase $2=$ constant basal rate infusion plus $\mathrm{SC}$ injections; phase $3=$ constant basal rate infusion plus supplemental meal bolus infusions; phase $4=$ as in phase 3 , but basal rate lower during nighttime hours

sisting of eight samples drawn with Capilets (Böhringer, Mannheim, FRG) using the hexokinase method in whole blood. In addition, frequency of blood glucose values below $2.22 \mathrm{mmol} / 1$, number of hypoglycaemic episodes and attacks per week, and total insulin requirements were recorded. Glycosylated haemoglobin $\mathrm{A}_{1}\left(\mathrm{Hb}_{1}\right)$ was determined every 4 weeks using microcolumns (Bio-Rad, Richmond, California, USA). Probabilities were determined with the Student's paired t-test.

\section{Pilot Study}

Five Type 1 diabetic patients (numbers 1-5, Table 1) volunteered to participate after they had discussed details of the planned study and had given their informed consent. All work was performed in accordance with the principles of the Declaration of Helsinki.

Phase 1: Intensified Conventional Treatment. During phase 1, intensified conventional methods were used in an effort to optimize metabolic control. Over several months, patients were taught to use a reflectance meter (Glucose-meter, Wolf KG, Wuppertal, FRG) for self-monitoring of blood glucose and to adjust the $\mathrm{SC}$ insulin dosage accordingly. Two daily doses of mixed short- and long-acting insulin were used. At least two blood samples per day were checked by each patient and at least once a week a day-long profile of eight values was performed. Carbohydrate intake was limited to a maximum of $60 \%$ of the daily energy intake. The recommended range was $25-35 \mathrm{kcal} / \mathrm{kg}$ body weight. Three main meals and two to three snacks a day were recommended, although patients were allowed some freedom in scheduling.

Phases 2 and 3: Constant Basal Rate Plus Supplements. After phase 1, patients were fitted with portable, external Promedos pumps (Siemens, Erlangen, FRG) [6, 9]. The catheter was polyethylene, and commercial porcine insulin (Hoechst, Frankfurt, FRG) Type CS $40 \mathrm{U} / \mathrm{ml}$ or semi-synthetic human insulin Type $\mathrm{PH} 40 \mathrm{U} / \mathrm{ml}$ was chosen.

These external units were used to simulate pumps which infused insulin at a constant rate, two using IV insulin infusion and the other three using the IP route. The basal rate dose was based on predicted insulin needs as determined using the closed-loop system (Biostator, Miles, Indianapolis, Indiana, USA). Additional insulin requirements at mealtimes were supplied by SC injections during one 4-week period (phase 2), and delivered by the external pump during another 4week period (phase 3). Three patients used phase 2 followed by phase 3, while the other two patients reversed the order. The decision as to which order a patient would use was made at random. Self-monitoring of blood glucose levels continued. Three main meals with a carbohydrate content of $50-60 \%$ were allowed, with a completely free schedule.

Phase 4: Dual Basal Rate Plus Supplements. During phase 4, external Promedos pumps were used to simulate what might be achieved with remote-controlled implants in an optimal meal-adjusted insulin profile. Three to five meals were eaten within a time schedule determined by the patient himself. Two basal rates were set with that required from $2400 \mathrm{~h}$ to $0700 \mathrm{~h} 10-20 \%$ lower than the rate during the waking hours.

\section{Implant Study}

Patients. After the pilot study, five patients volunteered for implantation of an Infusaid constant basal rate pump and gave informed consent. Patients 1 and 2 had taken part in the pilot study. Two other Type 1 patients (numbers 6 and 7), who had been extremely unstable on conventional treatment, had had extensive experience using external pumps before implantation. Patient 8 had developed diabetes following pancreatectomy. He had spent 1 month as a hospital in-patient learning self-monitoring, but before implantation he had achieved only poor metabolic control. As in the pilot study, all work was performed in accordance with the principles of the Declaration of Helsinki. 
Table 3. Comparison of metabolic control under intensified conventional treatment and constant basal rate infusion plus SC injection

\begin{tabular}{|c|c|c|c|c|c|c|c|c|c|c|c|}
\hline \multirow{3}{*}{$\begin{array}{l}\text { Patient } \\
\text { number }\end{array}$} & \multicolumn{2}{|l|}{$\mathrm{HbA}_{1}(\%)$} & \multirow{2}{*}{\multicolumn{2}{|c|}{$\begin{array}{l}\text { Mean blood glucose } \\
(\mathrm{mmol} / \mathrm{l})\end{array}$}} & \multirow{2}{*}{\multicolumn{2}{|c|}{$\begin{array}{l}\text { Hypoglycaemia } \\
\text { (per week) }\end{array}$}} & \multicolumn{4}{|c|}{ Insulin (U/day) } & \multirow{3}{*}{$\begin{array}{l}\text { Implant days } \\
\text { to } \\
1 \text { August } 1982\end{array}$} \\
\hline & \multirow[t]{2}{*}{$\mathrm{ICT}$} & \multirow[t]{2}{*}{ CBI } & & & & & \multicolumn{2}{|l|}{$\mathrm{ICT}$} & \multicolumn{2}{|l|}{$\mathrm{CBI}$} & \\
\hline & & & $\mathrm{ICT}$ & $\mathrm{CBI}$ & ICT & CBI & Depot & $\begin{array}{l}\text { Short- } \\
\text { acting }\end{array}$ & Basal & Injection & \\
\hline 1 & 13.0 & 8.8 & $12.2 \pm 5.7$ & $7.0 \pm 1.5$ & 2.2 & 0.5 & $36 \pm 6$ & $20 \pm 8$ & $33 \pm 3$ & $16 \pm 4$ & 191 \\
\hline 2 & 11.3 & 9.6 & $11.6 \pm 6.0$ & $6.7 \pm 1.2$ & 3.4 & 1.5 & $37 \pm 4$ & $18 \pm 10$ & $36 \pm 2$ & $16 \pm 2$ & 116 \\
\hline 6 & 12.6 & 9.8 & $13.0 \pm 5.9$ & $7.4 \pm 0.6$ & 2.5 & 0.7 & $32 \pm 6$ & $14 \pm 2$ & $30 \pm 4$ & $12 \pm 4$ & 41 \\
\hline 7 & 13.4 & 9.7 & $13.1 \pm 5.2$ & $7.1 \pm 0.8$ & 3.2 & 0.3 & $44 \pm 8$ & $24 \pm 2$ & $42 \pm 2$ & $18 \pm 4$ & 40 \\
\hline 8 & 10.7 & 8.9 & $11.6 \pm 3.4$ & $7.9 \pm 0.6$ & 0.1 & 0.1 & 32 & 0 & $11 \pm 2$ & 0 & 144 \\
\hline \multirow[t]{2}{*}{ Mean $\pm S D$} & & $\begin{array}{l}9.3 \pm 0.5 \\
0.001\end{array}$ & $\begin{array}{r}12.3 \pm 0.7 \\
p<\end{array}$ & $7.2 \pm 0.5$ & $2.0 \pm 1.2$ & $0.6 \pm 0.5$ & $36 \pm 5$ & $19 \pm 4$ & $30 \pm 11$ & $14 \pm 3$ & Total \\
\hline & \multicolumn{2}{|c|}{$p<0.001$} & \multicolumn{2}{|c|}{$p<0.001$} & \multicolumn{2}{|c|}{$p<0.001$} & \multicolumn{2}{|c|}{$p<0.01$} & \multicolumn{2}{|c|}{$p<0.01$} & 532 \\
\hline
\end{tabular}

$\mathrm{ICT}=$ Intensified conventional treatment $\mathrm{CBI}=$ constant basal rate infusion plus $\mathrm{SC}$ injections. Results expressed as mean $\pm \mathrm{SD}$

Surgical Procedures. The IP infusion route was chosen and the technique developed by Irsigler et al. was used [13]. Details of the surgical insertion of the catheter and implantation techniques for the device are described elsewhere $[14,15]$.

Study Protocol. The amount of long-acting insulin necessary for each patient before implantation was used as the basis for calculating the basal insulin infusion rate, and this basal rate was delivered by the pump beginning the second week after implantation. In addition to the infusion through the implanted device, patients were instructed to determine blood glucose values with a reflectance meter (Glucosemeter), and on this basis to inject a self-determined dose of short-acting insulin before breakfast and again before each meal.

Pumps and Catheters. The model 100 Infusaid pump was used, with basal rate flow set between 1.5 and $3.0 \mathrm{ml} / \mathrm{day}$. Technical details have been published previously [16]. A silicon catheter, $30 \mathrm{~cm}$ long with an inner diameter of $0.3 \mathrm{~mm}$ was used.

Insulin. A modification of Buchwald and Rohde's specifications [17] was used for filling the Infusaid pumps: insulin (Novo, $500 \mathrm{U} / \mathrm{ml}$ ) mixed with $75 \%-87 \%$ glycerol $(\mathrm{v} / \mathrm{v})$. In addition, phenol $0.2 \%$ and $1.2 \mathrm{ml}$ sodium bicarbonate $(1 \mathrm{mmol} / \mathrm{l})$ were added.

\section{Results}

\section{Pilot Study}

During phase 1 , metabolic control was poor, but was significantly improved for all tabulated parameters during each of phases $2-4$, which were comparable with one another (Table 2).

\section{Implant Study}

All implants are still functioning, and there have been no technical or medical complications to date. In all five patients, the mean blood glucose levels were significantly lower than those under intensified conventional treatment (Table 3 ). $\mathrm{HbA}_{1}$ levels fell significantly in all instances. The frequency of hypoglycaemic episodes was much lower, and there was no reported incidence of hypoglycaemic attack or coma. Insulin needs were slightly lower.

\section{Discussion}

Our data clearly show that the quality of metabolic control can be improved greatly when continuous insulin infusion is used rather than subcutaneous injections alone. In addition, despite this significantly improved blood glucose picture, it is possible to reduce the amount of insulin needed for a $24-\mathrm{h}$ period by about $30 \%$ with continuous infusion treatment.

The question of whether or not this reduction can be attributed to use of the intraperitoneal route is open to discussion $[5,18-19]$. It is a fact that $70 \%$ of the insulin delivered to the upper quadrant of the peritoneal cavity passes through the portal system into the liver [18], where it plays a central role in blood glucose homeostasis. Of the insulin which enters the liver, only $20 \%$ enters the systemic circulation [20]. Thus, peripherally-measured insulin values are rather uninformative about indicating the degree of insulinization of the entire organism. Since, in addition to being poor indicators, the measurement of free insulin values is difficult, we have stopped making these determinations.

A thorough discussion of types of insulin and their problems, the possible risks of catheters, and pros and cons of various routes of infusion are found in previous publications [1-7, 13-15]. No problems have been found with filling the insulin reservoir in the Infusaid device. The implantable device only minimally disturbs the appearance of the patient.

For our patient group, the most impressive result of the implant study was disappearance of the almost uncontrollable instability, with its extreme swings of blood glucose levels. During the implant phase of our study with over 530 patient days to date, there has not been a single event of unconsciousness, and since they recovered from the surgery of implantation, these patients, so very unstable under conventional treatment, have not spent a single day in hospital as an in-patient.

Acceptance of the implanted pumps has been excellent, since patients have been able to lead near-normal life styles. Even though a patient must inject extra insulin before large meals in addition to the basal dose delivered by the Infusaid device, this disadvantage is cheerfully accepted when the reward of freedom in scheduling meals is allowed and when it is seen that considerably more carbohydrate may be consumed at one time if desired.

We should emphasize that the principles of therapy 
described here are recommended for those unstable patients who have the day-to-day problems and dangers of hypoglycaemia or metabolic derangement on the one hand and the risks of late complications and the possibility of progressive deterioration on the other.

We feel that any treatment of diabetic patients with insulin delivery devices, which of necessity must be used for years, can only be accomplished when the units can be worn internally. When the danger of infection is reduced, the intraperitoneal or intravenous route may be chosen, and interference with a patient's normal life is at a minimum.

Of the 32 insulin delivery devices in the world already implanted in man, 24 are Infusaid pumps, while the rest are various programmable units, some of which have already been explanted [21]. At the present state of the art, the complex devices are still prone to breakdown. The Infusaid pump, however, fulfils the requirements that one sets for an instrument which must be used for many years: long-term reliable performance, safety and adequate metabolic control, even though the latter goal is only reached by giving additional daily injections.

Certain modifications for the Infusaid can be suggested. A flow restrictor that would make a unit independent of air pressure and of body temperature would be welcome, although in our patient group the observed flow-rate variation was only $\pm 10 \%$. The ability to program two basal rates so that the constant flow during the night could be reduced, and the ability to apply a bolus rate, as recommended by Buchwald et al. [11], would be useful. It might then be possible to eliminate the two extra demand subcutaneous injections.

Since it is already possible with our present technology for very unstable Type 1 diabetic patients to achieve a considerable improvement in metabolic control using relatively simple implantable insulin infusion devices, we suggest that this approach offers a viable therapeutic option, and that it may be used as a basis for a controlled clinical prevention trial in a selected group of patients.

Acknowledgements. We are grateful to Dr. C. Najemnik for supervision and work with patients and to the Biostator team: E. Exner, N. Hammerschmidt, J. Keiblinger and E. Postmann.

\section{References}

1. Irsigler K, Kritz H (1979) Long-term continuous intravenous insulin therapy with a portable insulin dosage-regulating apparatus. Diabetes 28: 196-203

2. Irsigler K, Kritz H, Kaspar L, Braendle J, Koller W, Franetzki M (1978) Preprogrammed insulin infusion with a portable pump system. In: Hepp KD, Kerner W, Pfeiffer EF (eds) Proceedings of feedback controlled and preprogrammed insulin infusion in diabetes mellitus. Workshop Reisensburg, FRG. Georg Thieme, Stuttgart New York, pp 193-197

3. Irsigler K, Kunz NK, Owens DR, Regal N (1980) New approaches to insulin therapy. MTP Press, Lancaster

4. Irsigler K, Kritz H (1980) Zur klinischen Anwendung der Insulininfusion im open-loop System. Gesamte Inn Med 1:8-19
5. Irsigler K, Kritz H (1980) Alternate routes of insulin delivery. Diabetes Care 3: 219-228

6. Irsigler K, Kritz H (1982) Improvement of insulin therapy for diabetics through pump treatment. In: Peterson CM (ed) Diabetes management in the 80's. Praeger Publishers, New York, pp 218-234

7. Kritz H, Irsigler K (1982) Continuous open loop infusion. Comparison of IV and SC insulin infusion with SC conventional treatment in unstable Jod's. In: Federlin K, Pfeiffer EF, Raptis S (eds) Islet-pancreas transplantation and artificial pancreas. Georg Thieme, Stuttgart New York, pp 297-300

8. Editorial (1980) Subcutaneous injections and absorption of insulin. Lancet 1: 1005-1006

9. Spencer WJ (1981) A review of programmed insulin delivery systems. Trans Biomed Engin 28: 237-251

10. Blackshear PJ, Rohde TD, Prosl F, Buchwald H (1979) The implantable infusion pump: a new concept in drug delivery. Med Progr Techn 6: 149-161

11. Buchwald H, Rohde TD, Dorman F, Skakoon J, Wigness B, Prosl F, Tucker E, Rublein T, Blackshear PJ, Varco R (1980) A totally implantable drug infusion device: laboratory and clinical experience using a model with single flow rate and new design for modulating insulin infusion. Diabetes Care 3: 351-358

12. Buchwald H, Varco R, Rupp WM, Goldberg FJ, Barbosa J, Rohde TD, Schwartz RA, Rublein T, Blackshear PJ (1981) Treatment of a Type 2 diabetic by a totally implantable insulin device. Lancet 1 : 1233-1235

13. Irsigler K, Kritz H, Hagmüller G, Franetzky M, Prestele K, Thurow $\mathrm{H}$, Geisen $\mathrm{K}$ (1981) Long-term continuous intraperitoneal insulin infusion with an implanted remote-controlled infusion device. Diabetes 30: 1072-1075

14. Kritz H, Hagmüller G, Buchwald H, Denck H, Najemnik C, Irsigler K (1983) Constant basal rate infusion of insulin with an implanted drug infusion device in insulin dependent maturity-onset diabetics. In: Brunetti P (ed) International symposium on artificial systems for insulin delivery, Assisi, September 1981. Raven Press, New York (in press)

15. Hagmüller G (1983) Implantation of insulin delivery devices. In: Irsigler K, Kritz H, Lovett R (eds) Diabetes treatment with implantable infusion systems. Urban and Schwarzenberg, Munich Vienna Baltimore (in press)

16. Blackshear PJ, Dorman FD, Blackshear Jr PL, Varco RL, Buchwald $H$ (1970) A permanently implantable self recycling low flow constant rate multi-purpose infusion pump of simple design. Surg Forum 21: 136-138

17. Rupp WM, Barbosa JJ, Blackshear PJ, McCarthy HB, Rohde TD, Goldenberg FJ, Rublein TG, Dorman FD, Buchwald H (1982) The use of an implantable insulin pump in the treatment of Type II diabetes. N Engl J Med 307: 265-270

18. Schade DS, Eaton RP (1980) The peritoneum - A potential insulin delivery route for mechanical pancreas. Diabetes Care 3:229-234

19. Marliss EB, Caron D, Albisser AM, Zinman B (1981) Present and future expectations regarding insulin infusion systems. Diabetes Care 4: 325-327

20. Waldhaeusl W, Bratusch-Marrain P, Gasic S, Korn A, Nowotny P (1979) Insulin production rate following glucose ingestion estimated by splanchnic C-peptide output in normal man. Diabetologia $17: 221-227$

21. Knatterud $G$ (1983) First report from implant registration system. In: Irsigler K, Kritz H, Lovett R (eds) Diabetes treatment with implantable infusion systems. Urban und Schwarzenberg, Munich Vienna Baltimore (in press)

Received:

and in revised form:

Dr. K. Irsigler

Third Medical Department

City Hospital Vienna-Lainz

Wolkersbergenstraße 1

A-1130 Vienna, Austria 